\title{
STUDY OF DRUG UTILIZATION PATTERNS IN POSTPARTUM WOMEN IN GOVERNIMENT MEDICAL COLLEGE, JAMIMU (INDIA).
}

KEY WORDS: Postnatal period, drug utilization pattern, drug rationalization

\section{Dr. Sanjay \\ Sharma* \\ Dr. Rashmi \\ Sharma \\ Dr. Mushtaq \\ Ahmed}

\section{Dr Zahid Gilani}

MBBS, MD Assistant Professor, Dept. of Pharmacology GMC,Doda. *Corresponding Author

MBBS, MD Medical Officer J\&K Health services Distt. Hospital Sarwal Jammu.

Ph D Pharmacology. Professor and Head Department of Pharmacology, GMC,Doda

MBBS , MD .Former Prof and Head deptt. of pharmacology and Ex- Principal GMC Jammu and Ex-Principal GMC Rajouri.

Background: There is a paucity of literature regarding rational prescribing practices especially during postnatal period. It was found worthwhile to assess the drug utilization patterns during postpartum period. It is known fact that the drugs prescribed during postnatal period have significant impact on the health of both mother and child. Material and Methods: A total of 1300 prescriptions of the patients which include 552 caesarian sections (cs) and 748 pervaginal (pv) delivery were randomly selected and studied. Results: It was recorded that the average number of drugs prescribed per prescription were 6.01 in cs patients and 10.95 in pv delivery group. The most commonly drugs that were prescribed were Antibiotics, analgesics, anti-inflammatory drugs, nutritional supplements (iron, calcium, multivitamins), H2 blockers and proton pump inhibitors (PPIs). In addition the other drugs included were oxytocin, prostaglandins, uetrine relaxants, antihyperttensives, bronchodilators, benzodiazepines, antifungal agents and antiepileptics. It was also found that $36.88 \%, 16.75 \%, 80.71 \%$ and $6.33 \%$ drugs prescribed were fixed dose combinations, generics, essential drugs and off label respectively in cs patients. Whereas, $42.96 \%, 13.23 \%, 78.81 \%$ and $8.2 \%$ drugs prescribed were fixed dose combinations, generic, essential drugs and off label respectively in pv patients. Conclusion: The results of this study reveals that there is need for educating prescribers regarding rational prescribing practices, especially during postnatal period when health of both infant and mother is at stake.

\section{Introduction}

Drug utilization research as defined by WHO is the marketing, distribution, prescription and use of drugs in a society with special emphasis on the resulting medical, social and economic consequences. ${ }^{[6]}$ Rational use of drugs requires that patient receives medication appropriate to their clinical needs in right dose for an adequate period of time and at the lowest cost. Pregnant women have been often excluded from clinical trials and evidences generated from animal-based studies are not often suitable for extrapolation to indicate teratogenicity in humans. Hence, drug use by pregnant women is considered experimental in most clinical practices. ${ }^{[2]}$ During pregnancy, new medical problems can develop and old ones can get exacerbated (e.g. migraine, headache, anemia) requiring drug therapy. Failure in managing conditions like these may affect the health of both the mother and her infant. ${ }^{[4]}$ During delivery and postpartum period, antibacterial drugs play a very crucial role and their availability can reduce maternal mortality. ${ }^{[1]}$ During the postpartum period, many women face acute and chronic health problems such as cough/colds, infections, bowel problems, mastitis, headache, back pain, migraine, hypertension, depression, and need to take medication. A US based study showed that more than $50 \%$ of health professionals did not know that women taking most antiepileptics could breastfeed safely ${ }^{[3]}$.

Pattern of drug prescription has an important impact in altering many physiological and pathological conditions both in a favourable and unfavourable manner. Awareness of inherent risks involved with the use of drugs during pregnancy is increasing. Moreover, drugs prescribed during postpartum period has significant impact on the health of both mother and child. Hence, drugs should be prescribed rationally keeping in view the risk of adverse drug reactions, drug interactions and secretion of drugs in breast milk. Pharmacoepidemiologic studies could help in minimizing the inherent risks of drug use in Postpartum period by establishing the profile of drug consumption by evaluating the existing health services and by investigating the interventional measures. ${ }^{[7]}$ One study analyzed the pattern of drug utilization in different types of epilepsy and also looked into the extent of polytherapy. ${ }^{[3]}$ Very few studies could be made available demonstrating drug utilization pattern in post-partum women from India. ${ }^{[3,8]}$ Because of paucity of scientific literature regarding drug utilization pattern in postpartum women it was found worthwhile to undertake this study.

\section{Materials and Methods:-}

The present prospective cross-sectional study was conducted over a period of three months w.e.f September 2006 to November 2006 in the Postgraduate Department of Pharmacology and Therapeutics in collaboration with Postgraduate Department of Gynaecology and obstetrics (PGDGO) of a tertiary care institute. Before starting the study, permission was taken from Institutional Ethics Committee. Two investigators used to visit the in-door patient department of PGDGO on two fixed days of a week. A total of 1300 prescriptions were collected randomly after taking well informed consent of the patients or the attendants. All the prescriptions were photocopied and originals were returned back to the patients. At the end of study all the prescriptions were analysed for various study parameters like number of drugs prescribed, nature of drugs prescribed, dosage forms of drugs prescribed, fixed dose combinations prescribed, drugs prescribed by generic or brand names, drugs prescribed from essential drugs list of institution, etc.

\section{STATISTICAL ANALYSIS:}

Drugs used in patients after caesarean section (cS) and per vaginal $(p v)$ delivery were calculated separately. Results were expressed in percentage and inter group comparison (between cs and pv deliveries) were done by using chisquare test. p-value $<0.05$ was considered to be statistically significant. 


\section{RESULTS:}

A total of 1300 prescriptions of the patients which include 552 caesarian sections ( $c s)$ and 748 pervaginal $(p v)$ delivery were randomly selected and studied (table -1). In cs group, 57.97\% of patients were between 18-35 yrs. of age and $66.66 \%$ patients were primigravida. In pv group $61.49 \%$ patients were above 35 years of age and $61.22 \%$ were multigravida. Pregnancy associated diseases and other disease conditions were found in $191(34.60 \%)$ and $24(4.34 \%)$ patients in cs group and $201(26.57 \%)$ and $28(3.74 \%)$ patients in pv group respectively.

Average number of drugs prescribed per prescription were 6.01 in $c s$ patients and 10.95 in pv delivery group. Antibiotics, analgesics, anti-inflammatory drugs, nutritional supplements (iron, calcium, multivitamins), $\mathrm{H} 2$ blockers and PPIs were the most commonly prescribed drugs (table 2,3$)$. Other drugs included were oxytocin, prostaglandins, uterine relaxants, antihypertensives, bronchodilators, benzodiazepines, antifungal agents and antiepileptics.

Antibiotics constituted $45.08 \%(1496)$ and $23.34 \%$ of total drugs prescribed in cs and pv delivery groups respectively. Among the antibiotics cephalosporins, aminoglycosides and tinidazole were the most prescribed drugs in CS patients. Extended spectrum pencilling (amoxycillin/ampicillin) and metronidazole were commonly prescribed antibiotics in pv delivery patients. Among NSAIDs (non-steroidal antiinflammatory drugs) diclofenac sodium, serratiopeptidase and paracetamol were more frequently prescribed in cs patients. Whereas ibuprofen and paracetamol were commonly prescribed in $p v$ delivery patients. NSAIDS constituted $30.26 \%(1004)$ and $18.95 \%(1553)$ of drugs prescribed in $c S$ and $p v$ delivery patients respectively. Nutritional supplements constituted $24.59 \%(2015)$ of total drugs prescribed in pv delivery patients and 6.02\%(200) in cs group. H2 blockers and PPIs were $36.71 \%(1218)$ and $39.51 \%(3237)$ of drugs prescribed in cs and pv delivery patients-emetics, oxytocis, prostaglandins, antihypertensives, theophyllines, sedatives and steroids were other drugs prescribed, local ointments constituted $8.27 \%(678)$ of total drugs prescribed in $p v$ delivery group. $36.88 \%, 16.75 \%$, $80.71 \%$ and $6.33 \%$ drugs prescribed as fixed dose combinations, generic, essential drug list and off label respectively in cs patients. Whereas, $42.96 \%, 13.23 \%$, $78.81 \%$ and $8.2 \%$ drugs prescribed as fixed dose combinations, generic,essential drug list and off label respectively in $p v$ delivery patients. Any drug prescribed for wrong indication or in inadequate dose (less or more than recommended dose) or that is contraindicated in pregnancy and lactation was considered as off label use of drug.

\section{DISCUSSION:}

Drug concentration in breast milk is largely determined by maternal serum drug concentration. However, medications that are highly protein bound, having large molecular weights or poorly lipid-soluble tend not to enter breast milk in clinically important quantities. Moreover retrograde diffusion of the drug from the breast milk to plasma can remove a drug from milk even if mother has not emptied her breasts. ${ }^{[9]}$ In the early postpartum period, large gaps between the mammary alveolar cells allow many medications to pass through this milk that may not be able to enter mature milk. These gaps close by the second week of lactation. The nursing infants drug exposure depends upon on the drug depends on the drugs concentration in breast milk and the amount of breast milk consumed by the infant. ${ }^{[11,12]}$ In the present study antibiotics constituted $45.08 \% 23.34 \%$ of total drugs prescribed in cs and pv delevery groups respectively. Among the antibiotics cephalosporins, aminoglycosides and tinidazole were the commonly prescribed drugs in cs patients. Whereas extended-spectrum pencillins (amoxycillin/ ampicillin) and metronidazole were commonly prescrbed in pv delivery patients. Among NSAIDs, diclofenac sodium, serratiopeptidase, ibuprofen and paracetamol were commonly prescribed drugs in our study. Nutritional supplements constituted $24.59 \%$ of total drugs in pv delivery patients. H2 blockers and PPIs were $36.71 \%$ and $39.51 \%$ of drugs in cs and pv delivery patients. $36.88 \%-42.96 \%$ drugs prescribed as fixed dose combinations.

In an earlier study from India, apart from the use of nutritional supplements, most commonly prescribed drugs were analgesics (in $70 \%$ of patients in the hospital settings, $56 \%$ of the patients in the postnatal clinic and $37.6 \%$ patients in the community), and antibiotics ( $90 \%$ of the patients in the hospital setting, $86 \%$ of the patients in the postnatal clinic and $13 \%$ of the community based patients) during postnatal period. ${ }^{[8]}$ Anti-hypertensives, digoxin.bronchodilators and sedatives were the other drugs prescribed to admitted patients. Antibiotics like pencillins, ceohalosporins, trimethoprim-sulphamethoxazole, etc., were which are excreted in milk in trace amounts are compatible with breastfeeding. ${ }^{[12]}$ however trimethoprim-sulphamethoxazole should be avoided in women when nursing infants are younger than two months because of its potential for causing increased bilirubin levels. ${ }^{[8]}$ The amount of drugs like metronidazole, tinidazole etc., transferred to infants through breast milk is much lower than the therapeutic dosage for infants, and no adverse effects have been reported from exposure through breast milk..$^{[9]}$

$36.88 \%-42.96 \%, 13.23 \%-16.75 \%, 78.81 \%-80.71 \%$ and $6.33 \%-$ $8.2 \%$ drugs prescribed as fixed dose combinations, generic, essential drug list and off-label respectively in the present study. Prescribing under generic name is considered rational and economic, but $13.23 \%-16.75 \%$ generic drugs prescribed in our study, is much less than that reported earlier(74.38\%) from a tertiary care hospital of India. ${ }^{[13]}$ The Indian Medical Council (Professional Conduct, Etiquette and Ethics) Regulations, 2002 states that every physician should, as far as, possible prescribe drugs with generic names and he/she shall ensure that there is a rational prescription and use of drugs. ${ }^{[14]}$ It also goes on to state that it is not unethical for a physician to prescribe drugs as long as there is no exploitation of the patient and this should explicitly state the proprietary as well as generic name of the drug. ${ }^{[14]}$ Results of our study clearly indicated need for educating prescribers regarding rational prescribing practices, especially during postnatal period when health of both infant and mother is at stake. Our study could not assess the effects of parental drug use on infant and child development; hence, long-term studies are urgently required to assess the effects of parental drug use on infant and child development.

Table-1: Baseline characteristics of the patients

\begin{tabular}{|c|c|c|c|}
\hline S.No & Parameter & CS(n=552) & PV(n=748) \\
\hline 1 & Age $<18$ & $72(13.04 \%)$ & $68(9.09 \%)$ \\
\hline & Agel8-35 & $320(57.97 \%)$ & $220(29.41 \%)$ \\
\hline & Age $>35$ & $160(28.98 \%)$ & $460(61.49 \%)$ \\
\hline 2 & Primi & $368(66.66 \%)$ & $216(28.87 \%)$ \\
\hline 3 & Multi & - & $12(1.60 \%)$ \\
\hline 4 & Grand Multi & - & $3(0.4 \%)$ \\
\hline 5 & $\begin{array}{c}\text { Other Associated } \\
\text { disease states }\end{array}$ & $24(4.34 \%)$ & $28(0.4 \%)$ \\
\hline & Hypertension & 10 & 16 \\
\hline & Diabetes mellitus & 0 & 2 \\
\hline & Hypothyroidism & 2 & 1 \\
\hline & Epileptics & 4 & 2 \\
\hline & Tuberculosis & 4 & 4 \\
\hline & Others & 4 & 3 \\
\hline 6 & HIV status(checked) & $320(57.9 \%)$ & $142(18.98 \%)$ \\
\hline 7 & HIV +ve if checked & Nil & Nil \\
\hline 8 & Rh-veBlood group & $45(8.15 \%)$ & $70(9.36 \%)$ \\
\hline
\end{tabular}

|www.worldwidejournals.com 


\begin{tabular}{|c|c|c|c|}
\hline 9 & $\begin{array}{c}\text { H/O any drug } \\
\text { reaction }\end{array}$ & Nil & Nil \\
\hline 10 & $\begin{array}{c}\text { Pregnancy-induced } \\
\text { disease }\end{array}$ & & \\
\hline & PIH & $115(20.83 \%)$ & $175(23.39)$ \\
\hline & APH & $76(13.77 \%)$ & Nil \\
\hline & PID & Nil & $26(3.47 \%)$ \\
\hline
\end{tabular}

HIV=human immunodeficiency virus, $\mathrm{PIH}=$ pregnancy induced hypertension, APH=anti-partum haemorrhage, PID =pregnancy-induced diabetes, $\mathrm{CS}=$ caesarean section patients, $\mathrm{PV}=$ per vaginal delivery patients, $\mathrm{H} / \mathrm{O}=$ history.

Table -2:Percentage of drugs Prescribed during postpartum period-A

\begin{tabular}{|c|c|c|c|c|}
\hline $\begin{array}{l}\text { S. } \\
\text { No }\end{array}$ & $\begin{array}{c}\text { DRUGS } \\
\text { [NUMBER(\%)] }\end{array}$ & CS(n=552) & PV(n=748) & $\begin{array}{c}\mathbf{P} \\
\text { values }\end{array}$ \\
\hline \multicolumn{5}{|c|}{ Antimicrobials } \\
\hline 1 & Cephalosporins & $492(32.88 \%)$ & $145(7.45 \%)$ & \\
\hline 2 & Gentamicin & $532(35.56 \%)$ & $69(3.61 \%)$ & \\
\hline 3 & Amoxycillin & $44(2.94 \%)$ & $654(34.20 \%)$ & \\
\hline 4 & Ciprofloxacin & $24(1.60 \%)$ & $129(6.75 \%)$ & \\
\hline 5 & Ofloxacin & $16(1.06 \%$ & $32(1.67 \%)$ & \\
\hline 6 & Ampicillin & $116(7.75 \%)$ & $113(5.91 \%)$ & \\
\hline 7 & Tinidazole & $268(17.91 \%)$ & $173(9.05 \%)$ & \\
\hline \multirow[t]{2}{*}{8} & Metronidazole & $(0.27 \%)$ & $597(31.22 \%)$ & \\
\hline & Total & $1496(45.08 \%)$ & $1912(23.34 \%)$ & 0.0129 \\
\hline \multicolumn{5}{|c|}{ Analgesics } \\
\hline 1 & Diclofenac & $552(54.98 \%)$ & 186(11.97\%) & \\
\hline 2 & Serratiopeptidase & $324(32.37 \%)$ & $207(13.32 \%)$ & \\
\hline 3 & Mefenamic Acid & $4(0.39 \%)$ & $34(2.18 \%)$ & \\
\hline 4 & Tramadol & $40(3.98 \%)$ & $92(5.92 \%)$ & \\
\hline 5 & Ibuprofen & $4(0.39 \%)$ & 698944.94\%) & \\
\hline \multirow[t]{2}{*}{6} & Paracetamol & $80(7.96 \%)$ & $336(21.63 \%)$ & \\
\hline & Total & $1004(30.26 \%)$ & $1553(18.25 \%)$ & 0.542 \\
\hline
\end{tabular}

CS =caesarean section, PV =per vaginal delivery patients $\mathrm{n}=$ number of patients

Table 3:Percentage of drugs prescribed during postpartum period-B

\begin{tabular}{|c|c|c|c|c|}
\hline S.No & $\begin{array}{c}\text { Drugs } \\
\text { [number(\%)] }\end{array}$ & $\operatorname{CS}(n=552)$ & PV(n=748) & $\begin{array}{c}\mathbf{P} \\
\text { values }\end{array}$ \\
\hline \multicolumn{5}{|c|}{ Nutitional Spplements } \\
\hline 1 & Iron & $52(26 \%)$ & $591(29.33 \%)$ & \\
\hline 2 & Calcium & $44(22 \%)$ & $689(34.19 \%)$ & \\
\hline 3 & Multivitamins & $88(44 \%)$ & 723(35.88\%) & \\
\hline \multirow[t]{18}{*}{4} & VitaminE & $16(8 \%)$ & $12(0.59 \%)$ & \\
\hline & Total & $200(6.02 \%)$ & $2015(24.59 \%)$ & $0.04 *$ \\
\hline & Antiemetics & $160(4.82 \%)$ & $492(6 \%)$ & 0.987 \\
\hline & H2 blockers/PPI & $1218(36.71 \%)$ & $3237(39.51 \%)$ & 0.993 \\
\hline & Methergin & $72(2.16 \%)$ & $28(0.34 \%)$ & 0.719 \\
\hline & Oxytocin & $36(1.08)$ & $166(2.02 \%)$ & 0.962 \\
\hline & Prostaglandins & $50(2.41 \%)$ & $134(1.64 \%)$ & 0.986 \\
\hline & Isoxsuprine & $8(0.24 \%)$ & $18(0.21 \% 0$ & 0.999 \\
\hline & Nifedipine & $72(12.16 \%)$ & $231(2.82 \%)$ & 0.993 \\
\hline & Deriphylline & $8(0.24 \%)$ & $28(0.34 \%)$ & 0.999 \\
\hline & Diazepam & $24(0.72 \%)$ & $93(1.13 \%)$ & 0.992 \\
\hline & Phenytoin & $4(0.12 \%)$ & $4(0.05 \%)$ & 0.998 \\
\hline & Phenobarbitone & $48(1.45 \%)$ & $126(1.54 \%)$ & 0.999 \\
\hline & Local ointment & $8(0.24 \%)$ & $678(8.27 \%)$ & $0.041 \%$ \\
\hline & Antifungal & $8(0.24 \%)$ & $259(3.16 \%)$ & 0.466 \\
\hline & Corticosteroids & $28(0.84 \%)$ & $12(0.15 \%)$ & 0.921 \\
\hline & $\begin{array}{c}\text { Blood } \\
\text { Transfusion }\end{array}$ & $78(2.35 \%)$ & $88(1.07 \%)$ & 0.921 \\
\hline & Others & $69(2.08 \%)$ & $93(1.13 \%)$ & 0.972 \\
\hline
\end{tabular}

\begin{tabular}{|c|c|c|c|c|}
\hline & $\begin{array}{c}\text { Fixed dose } \\
\text { combinations }\end{array}$ & $1224(36.88 \%)$ & $3520(42.96 \%)$ & 0.85 \\
\hline & Drugs by generic & $556(16.75 \%)$ & $1084(13.23 \%)$ & 0.92 \\
\hline & $\begin{array}{c}\text { Drugs from } \\
\text { essential drug } \\
\text { list }\end{array}$ & $2678(80.71 \%)$ & $6457(78.81 \%)$ & 0.99 \\
\hline $\begin{array}{c}\text { Off label } \\
\text { prescription of } \\
\text { drugs }\end{array}$ & $210(6.33 \%)$ & $672(8.2 \%)$ & 0.96 \\
\hline
\end{tabular}

$\mathrm{CS}=$ caesarean section patients, $\mathrm{PV}=$ per vaginal delivery patients, $n=$ number of patients

\section{REFERENCES:}

1. Mohd. Sajid Khan. A Drug Utilization Study in Post-operative Patients of IPD Obstetrics and Gynaecology International Archives of BioMedical And Clinical ResearchVol 5 | Issue 4 | October-December 2019 (PH12-14).

2. Neim Bedewi 1, Mekonnen Sisay 2* and Dumessa Edessa3 Drug utilization pattern among pregnant women attending maternal and child health clinic of tertiary hospital in eastern Ethiopia: Consideration of toxicological perspectives. BMC Res Notes (2018) 11:858.

3. Moni R. Sahal*, Kath Ryan2 and Lisa H. Amir. Postpartum women's use of medicines and breastfeeding practices: a systematic review. Saha et al. International Breastfeeding Journal (2015) 10:28

4. Nargis Ibrahim Kureshee1, Priti Pravin Dhande2 Awareness of Mother and Doctors about Drug Utilization Pattern for Illnesses Encountered during Pregnancy. Journal of Clinical and Diagnostic Research. 2013 Nov, Vol-7(11): 2470-2474

5. Shobhana Mathur, Sumana Sen *, L Ramesh, Satish Kumar MUtilization pattern of antiepileptic drugs and their adverse effects, in a teaching hospital Asian Journal of Pharmaceutical and Clinical Research Vol.3 Issue 1, JanuaryMarch 2010(55-59)

6. Introduction to drug utilization research/WHO international working group for drug statistics methodology, WHO collaborating centre for drug utilization research and clinical pharmacological services . printed in oslo, Norway,2003.

7. Sharma R, Kapoor B, Verma U,Drug utilization pattern during pregnancy in north india.Indian J Med Sci,2006;60:277-87.

8. Uppal R,Karmakar S, SinghMM, Dhall GI, Gupta I, Sharma PL Prescription drug use in lactating mothers : an experience at a referral hospital and in a community in India. Int J Clin Pharmacol Ther Toxicol. 1993;31(2):93-5.

9. Hale TW,. Medications and Mother's milk :1999-2000. $8^{\text {th }}$ ed. Amarillo, Tex:Pharmasoft Medical,1999.

10. Breitzka RL, Sandritter TL,Hatzopoulos FK. Principles of drug transfer into breast milk and drug disposition in the nursing infant.J Hum Lact 1997;13:15558.

11. Powers NG, Slusser W. Breastfeeding update 2: clinical lactation management.Pediator Rev 1997;18:147-61.

12. American Academy of Pediatrics Committee on Drugs. The Transfer of drugs and other chemicals into human milk. Pediatrics 1994;93:137-50.

13. Medical Council of India. Indian Medical Council(Professional conduct,Etiquette and Ethics)Regulations, 2002. Gazette of Indiadated 06.04.02,part III, sectin 4

14. Das AK, Roy K, Kundu KK, Islam CN, Ram AK et.al. Study of rational utilization and cost $n=$ analysis of antimicrobials in a Government teaching Hospital.Ind JPharmacol 2002;34:59-61. 